\title{
Correction to: Understanding preservation and identification biases of ancient adhesives through experimentation
}

\author{
Paul R. B. Kozowyk ${ }^{1,2}$ (D) Annelou L. van Gijn ${ }^{1}$ • Geeske H. J. Langejans ${ }^{2,3}$ \\ Published online: 20 October 2020 \\ (C) Springer-Verlag GmbH Germany, part of Springer Nature 2020
}

Correction to: Archaeological and Anthropological Sciences (2020) 12: 209 https://doi.org/10.1007/s12520-020-01179-y

The original version of this article, unfortunately, contained errors. Author found out that there is an error in the funding declarations of the article. It should be:

Funding This project has received funding from Archon (grant holder P.R.B.K) project title: 'Sticking around: Identification, performance, and preservation of Palaeolithic adhesives' (grant number 022-005-016) and from the European Research Council (ERC) under the European Union's Horizon 2020 research and innovation programme, grant agreement number 804151 (grant holder G.H.J.L.).

Publisher's note Springer Nature remains neutral with regard to jurisdictional claims in published maps and institutional affiliations.

The online version of the original article can be found at https://doi.org/ $10.1007 / \mathrm{s} 12520-020-01179-\mathrm{y}$.

Paul R. B. Kozowyk

p.r.b.kozowyk@tudelft.nl

1 Faculty of Archeology, Leiden University, 2333 CC Leiden, the Netherlands

2 Faculty of Mechanical, Maritime and Materials Engineering, Delft University of Technology, 2628 CD Delft, the Netherlands

3 Palaeo-Research Institute, University of Johannesburg, Johannesburg 2092, South Africa 